OPEN ACCESS

Edited by:

Suying $X u$,

Beijing University of Chemical

Technology, China

Reviewed by:

Xin $W u$,

The University of Sydney, Australia

Qiuyu Gong,

Independent Researcher,

Singapore, Singapore

*Correspondence:

Tangxin Xiao

xiaotangxin@cczu.edu.cn

Specialty section:

This article was submitted to

Supramolecular Chemistry,

a section of the journal

Frontiers in Chemistry

Received: 25 September 2020

Accepted: 16 October 2020

Published: 19 November 2020

Citation:

Wu H and Xiao T (2020)

Supramolecular Polymers With AIE

Property Fabricated From a

Cyanostilbene Motif-Derived Ditopic

Benzo-21-Crown-7 and a Ditopic

Dialkylammonium Salt.

Front. Chem. 8:610093.

doi: 10.3389/fchem.2020.610093

\section{Supramolecular Polymers With AIE Property Fabricated From a Cyanostilbene Motif-Derived Ditopic Benzo-21-Crown-7 and a Ditopic Dialkylammonium Salt}

\author{
Haoran Wu and Tangxin Xiao* \\ School of Petrochemical Engineering, Changzhou University, Changzhou, China
}

Fluorescent supramolecular polymers (FSP) have attracted considerable attention in recent years. Particularly, the incorporation of aggregation-induced emission (AIE) property to the FSP will bring this material into practical applications. Herein, we designed and synthesized a cyanostilbene motif derived ditopic benzo-21-crown-7 (B21C7) as a host molecule $(\mathbf{H})$. The cyanostilbene motif endows $\mathbf{H}$ with AlE property while the B21C7 motif renders it with the capability to complex with electron deficient guest molecules. Upon the addition of a ditopic dialkylammonium salt molecule $(\mathbf{G})$, a novel FSP with blue luminescent property can be constructed. This B21C7-based host-guest FSP with blue fluorescence may have potential application in supramolecular luminescent materials.

Keywords: supramolecular polymer, AIE, host-guest, fluorescent materials, B21C7

\section{INTRODUCTION}

Supramolecular polymers, in which ordered and highly directional polymeric arrays of monomeric building blocks are brought together by reversible non-covalent bonds, are outstanding materials that generally exhibit stimuli-responsive and self-healing properties (Aida et al., 2012; Yang et al., 2015; Wehner and Würthner, 2020). The driving force of supramolecular polymers usually includes hydrogen bonds (Xiao et al., 2019b,e; Datta et al., 2020; Qi et al., 2020), metal-ligand bonds (Zheng et al., 2016; Shi et al., 2019), host-guest complexation (Guo et al., 2010; Harada et al., 2014; Wang et al., 2018; Xiao and Wang, 2018; Xiao et al., 2018, 2019d; Chen et al., 2019), donoracceptor interaction (Han et al., 2018), $\pi-\pi$ stacking (Wagner et al., 2019; Xiao et al., 2019c), or a combination of them (Li et al., 2012; Wei et al., 2015; Xiao et al., 2020b). In recent years, supramolecular fluorescent materials have drawn much attention, such as fluorescent molecular switches (Cheng et al., 2017), fluorescent sensors (Kumawat et al., 2019), fluorescent metallaclip (Wang et al., 2019), and artificial light-harvesting systems (Xiao et al., 2019g, 2020a). Particularly, the development of fluorescent supramolecular polymers (FSPs) has attracted more and more interest because of their potential application in the area of dynamic luminescent materials (Ji et al., 2013; Zhang et al., 2017, 2018; Li et al., 2019). Moreover, the emergence of aggregation-induced emission (Hong et al., 2011) (AIE) fluorophores laid the foundation for the application of FSP in practice.

Macrocycle-based host-guest interaction is an important driving force in supramolecular chemistry. For example, we have reviewed a series of supramolecular materials based on 
pillararene (Xiao et al., 2019a,f,h). Benzo-21-crown-7 (B21C7) is one of the most important crown ethers (Zhang et al., 2007), and it shows interesting applications like adhesive materials (Dong et al., 2017; Zhang et al., 2019). B21C7 is the smallest crown ether that can complex with dialkylammonium salts, leading to a relatively strong host-guest interaction. Cyanostilbene is a wellknown fluorophore and shows interesting AIE behavior, which is usually used for the construction of rotaxanes (Lee et al., 2013), nanoparticles with near-infrared emission (Shi et al., 2016), hydrogen-bonded supramolecular polymer (Lavrenova et al., 2017), and light-harvesting system (Kim et al., 2018; Sun et al., 2020). To the best of our knowledge, the integration of B21C7 unit and cyanostilbene unit to a host molecule to construct FSP has not yet been reported so far.

Previously, we have reported some orthogonal supramolecular polymers based on B21C7 (Xiao et al., 2013, 2020c). Herein, we designed and synthesized a new host molecule $\mathbf{H}$, which bears both cyanostilbene motif and B21C7 units (Figure 1). The cyanostilbene motif endows $\mathbf{H}$ with the property of AIE, while B21C7 unit endows $\mathbf{H}$ with the capability to bind dialkylammonium salt. In the presence of guest molecule G (a ditopic dialkylammonium salt compound), a novel AA/BBtype FSP can be fabricated by crown ether-based host-guest complexation. Furthermore, the FSP could be assembled into macroscopic fibers with blue fluorescence from concentrated solution. This crown ether-based FSP with beautiful blue fluorescence both in solution and in the solid state may have potential application in supramolecular luminescent materials.

\section{RESULTS AND DISCUSSIONS}

\section{Synthesis}

The synthesis of organic molecules $\mathbf{H}$ and $\mathbf{G}$ are straightforward. Compound $\mathbf{H}$ was synthesized from B21C7-based derivative A (Lu et al., 2018) and cyanostilbene-derived compound 5 (Scheme 1). As shown in Scheme 1, starting from p-anisaldehyde and 4-methoxybenzyl cyanide, compound $\mathbf{4}$ was prepared in ethanol solution by condensation reaction. Demethylation of compound $\mathbf{4}$ with boron tribromide in dichloromethane (DCM) yields compound 5 (Gu et al., 2012). Compound G was synthesized according to literature report (Li et al., 2018). The compounds that have not been reported previously are carefully characterized by ${ }^{1} \mathrm{H}$ NMR, ${ }^{13} \mathrm{C} \mathrm{NMR}$, and HR-MS (Supplementary Figures 1-4).

\section{AIE and Vapochromic Behavior of $\mathbf{H}$}

In order to examine whether the cyanostilbene motif bridged B21C7 is AIE active, the fluorescence spectra of $\mathbf{H}$ in mixed $\mathrm{H}_{2} \mathrm{O} /$ Tetrahydrofuran (THF) solutions were investigated. As shown in Figure 2, $\mathbf{H}$ shows an obvious AIE behavior. There is no fluorescence emission when $\mathbf{H}$ was in pure THF (a good solvent for $\mathbf{H}$ ). When water (a poor solvent for $\mathbf{H}$ ) content was increased gradually to $80 \%$, a moderate emission was observed. The absorption spectrum of $\mathbf{H}$ is shown in Supplementary Figure 5. The emission wavelength was at $480 \mathrm{~nm}$ when exited at $365 \mathrm{~nm}$. Upon increasing water content to $95 \%$, the fluorescence intensity of $\mathbf{H}$ exhibits a dramatic enhancement with a bright blue color.

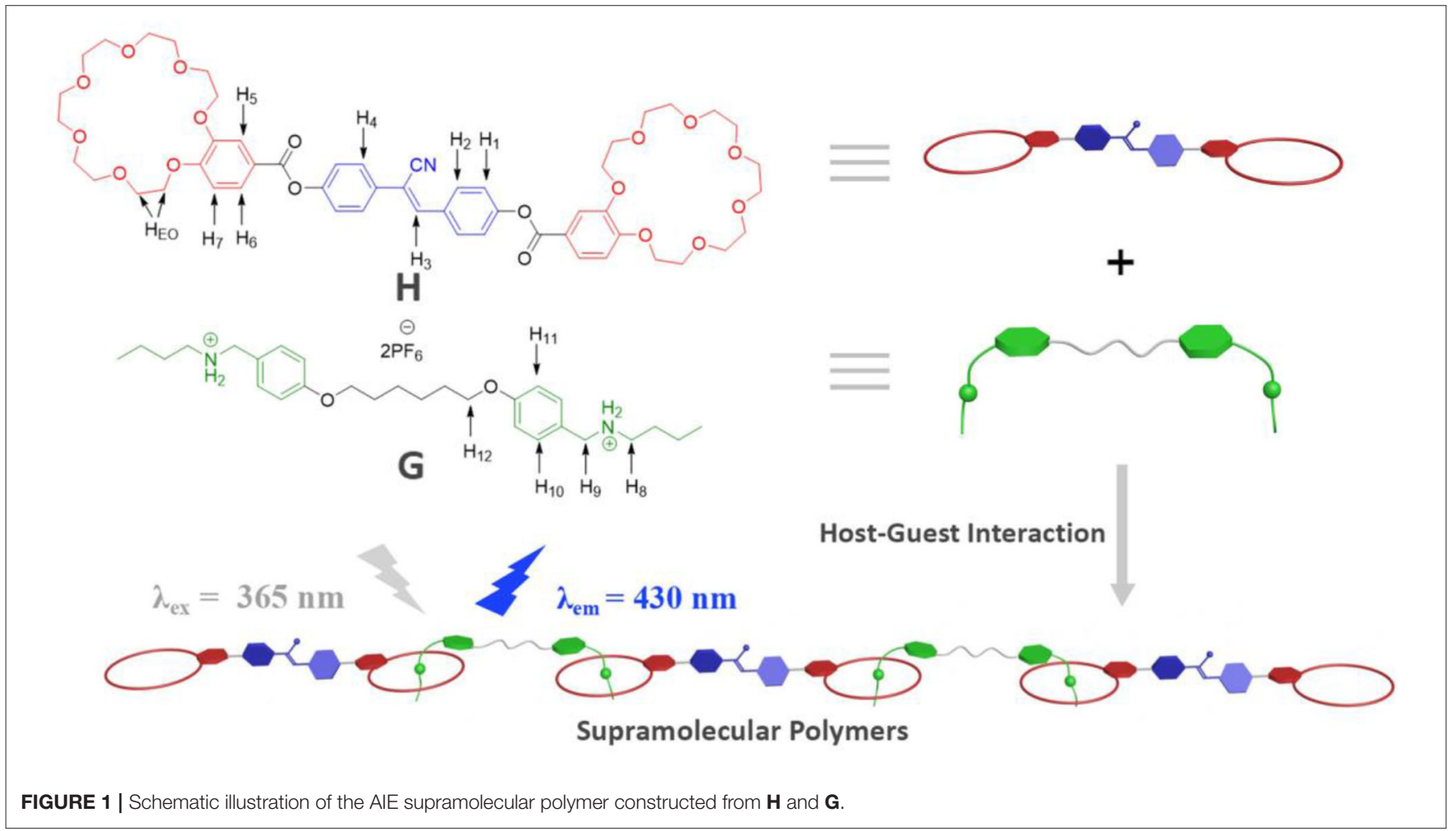




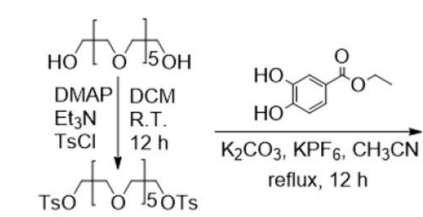

1

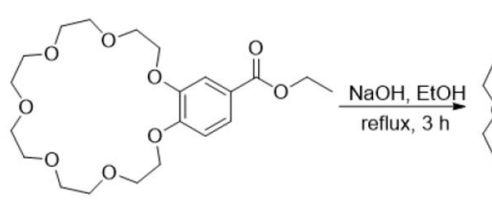

2

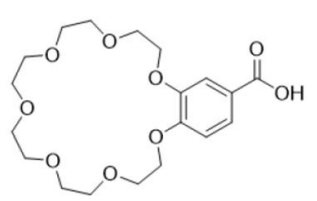

3

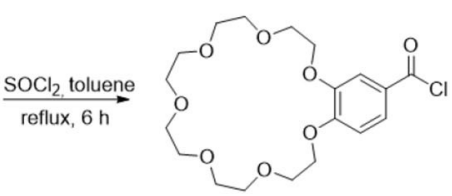

A
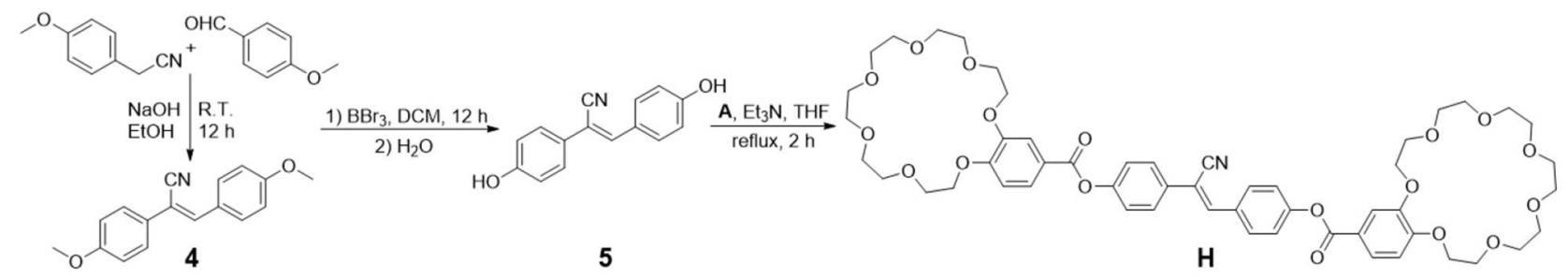

SCHEME 1 | Synthetic route of compound $\mathbf{H}$.

A

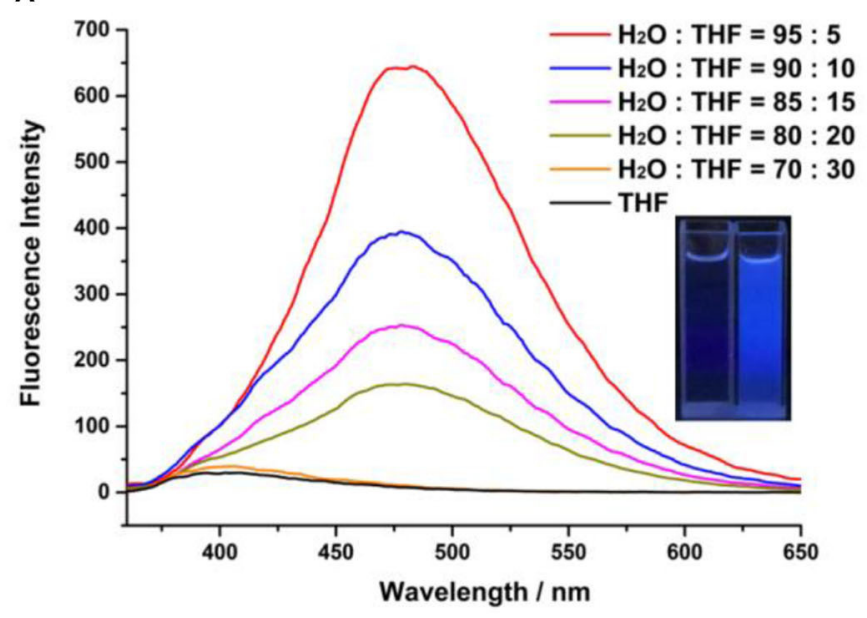

B (i)
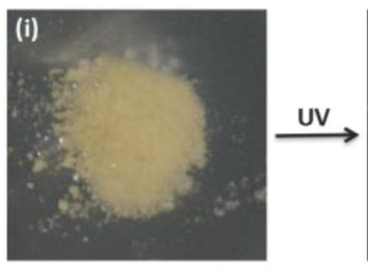

(iv)

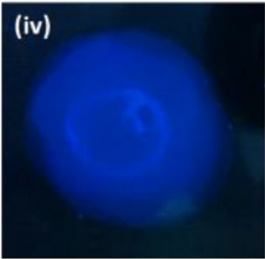

(ii)

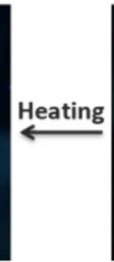

(iii)

FIGURE 2 | (A) Fluorescence emission spectra of $\mathbf{H}$ versus $\mathrm{H}_{2} \mathrm{O}$ fraction in THF/ $\mathrm{H}_{2} \mathrm{O}$ mixtures $\left(\lambda_{\text {ex }}=365 \mathrm{~nm}\right.$, [H] $\left.=5 \times 10^{-5} \mathrm{M}\right)$. Inset: photographs of $\mathbf{H}$ in THF and $\mathbf{H}$ in THF/ $/ \mathrm{H}_{2} \mathrm{O}=5$ : 95 mixtures $\left([\mathbf{H}]=5 \times 10^{-5} \mathbf{M}\right)$; and $(\mathbf{B})$ solid powder of $\mathbf{H}$ under natural light (i) and UV light (ii), fumigation with DCM (iii), and color recovered by heating (iv).

The dried powder of $\mathbf{H}$ was obtained as a light yellow solid, which exhibited intense blue luminescence under irradiation at $365 \mathrm{~nm}$ at room temperature (Figure 2B). Interestingly, exposing the sample to DCM vapor resulted in a distinct change of color from blue to green within only $30 \mathrm{~s}$ (Figure 2B). Notably, the blue color can be recovered by heating the sample to remove the DCM (Figure 2B).

\section{Supramolecular Polymerization Studied by ${ }^{1} \mathrm{H}$ NMR and Viscometry}

Supramolecular polymerization of $\mathbf{H}$ and $\mathbf{G}$ was first investigated by concentration-dependen ${ }^{1} \mathrm{H}$ NMR. It was measured in mixed $\mathrm{CDCl}_{3} / \mathrm{CD}_{3} \mathrm{CN}(1: 1, \mathrm{v} / \mathrm{v})$ at concentrations in the range of 2-64 mM (Figure 3). The concentration-dependent ${ }^{1} \mathrm{H} \mathrm{NMR}$ spectra showed a complex picture owing to the slow-exchange complexation of the B21C7 motif with the dialkylammonium salt on the NMR timescale. It should be noted that the peak splitting is relatively sharp at low concentrations (2$8 \mathrm{mM}$ ), suggesting that the cyclic oligomers are predominant species at this stage. As the concentration increases, these peaks became broad, indicating the formation of high-molecularweight assemblies, such as supramolecular polymers. By contrast, the concentration-dependent ${ }^{1} \mathrm{H}$ NMR spectra of individual $\mathbf{H}$ shows no chemical shift change upon concentration increasing (Supplementary Figure 6).

To further study the supramolecular polymerization driven by crown ether-based host-guest interaction, viscosity measurements were performed by using a micro-Ubbelohde viscometer. A double logarithmic curve of specific viscosity toward monomer concentration is depicted in Figure 4. During 


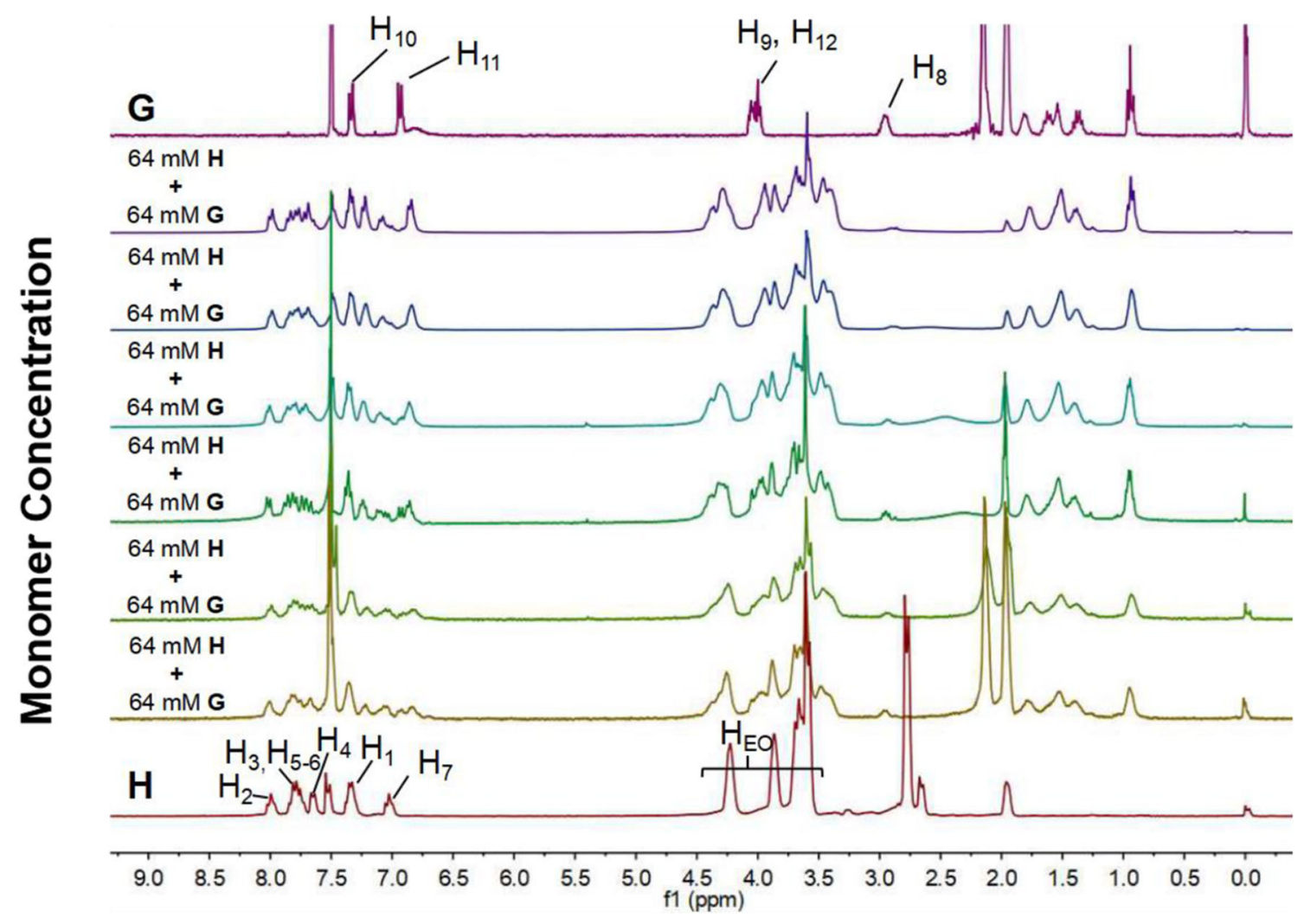

FIGURE 3 $\mid{ }^{1} \mathrm{H}$ NMR spectra $\left(300 \mathrm{MHz}, \mathrm{CDCl}_{3} / \mathrm{CD}_{3} \mathrm{CN}=1 / 1, \mathrm{v} / \mathrm{v}, 298 \mathrm{~K}\right)$ of individual $\mathbf{H}$ and $\mathbf{G}$, and mixtures of them at different monomer concentrations $([\mathbf{H}] /[\mathbf{G}]=1 / 1)$.

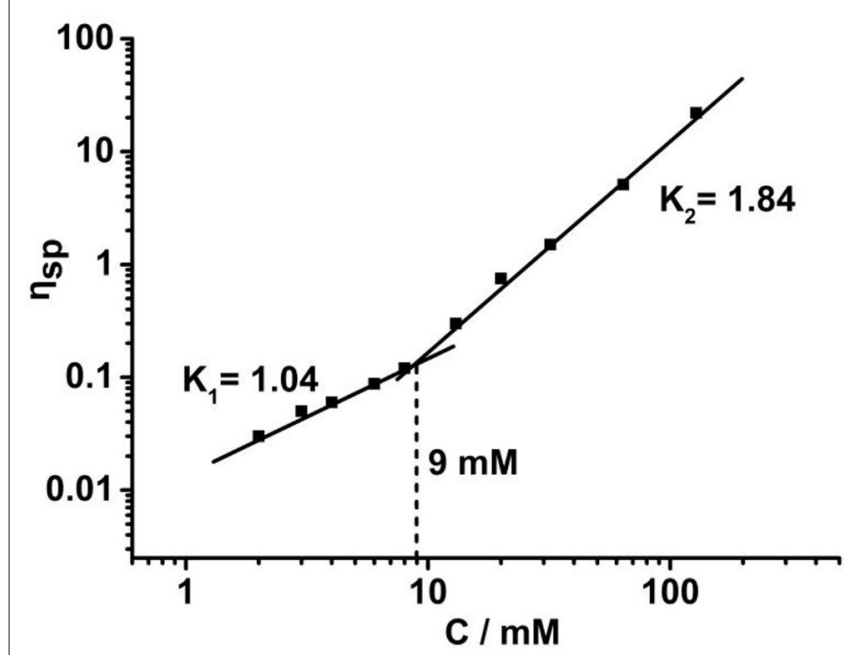

FIGURE 4 | Specific viscosity of $\mathbf{H} / \mathbf{G}$ complex vs. the monomer concentration in $\mathrm{CDCl}_{3} / \mathrm{CH}_{3} \mathrm{CN}(1: 1, \mathrm{v} / \mathrm{v})$ solutions $(298 \mathrm{~K})$.

the low concentration range, the slope value was tested to be 1.04, which is the characteristic of cyclic oligomers with constant size. When the concentration increased to $9 \mathrm{mM}$, a steeper curve with a slope 1.84 was obtained, suggesting that the cyclic oligomers are gradually transformed into supramolecular polymers. This phenomenon was in line with concentration-dependent ${ }^{1} \mathrm{H}$ NMR.

\section{Solid-State Fluorescence Spectroscopy}

The formation of supramolecular polymers was further evidenced by its processibility. Fibers can be drawn from a concentrated solution of the host and guest with a molar ratio of $\mathbf{H} / \mathbf{G}=1 / 1$ (Figure 5A). Such fibers can be only made from entanglements of large aggregates. By contrast, no fiber can be pulled out from the concentrated solution of individual $\mathbf{H}$ or individual $\mathbf{G}$. The fiber is colorless under visible light (Figure 5A) and generates blue fluorescence under UV light (Figure 5B). This fiber still has fluorescent luminescence after preparation for several days, indicating that the supramolecular polymer has potential applications in the area of supramolecular luminescent materials. The photophysical property of the supramolecular polymer was further investigated by solidstate fluorescence spectroscopy. As shown in Figure 5C, the emission wavelength of $\mathbf{H}$ shows a hypochromic shift from $480 \mathrm{~nm}$ in solution to $415 \mathrm{~nm}$ in the solid state. Compared with individual $\mathbf{H}$, the supramolecular polymer in the solid state exhibited a stronger emission and bathochromic shift to $430 \mathrm{~nm}$, indicating that the incorporation of the guest affected the packing of the fluorophores in the solid state, resulting in modified luminescent properties. 

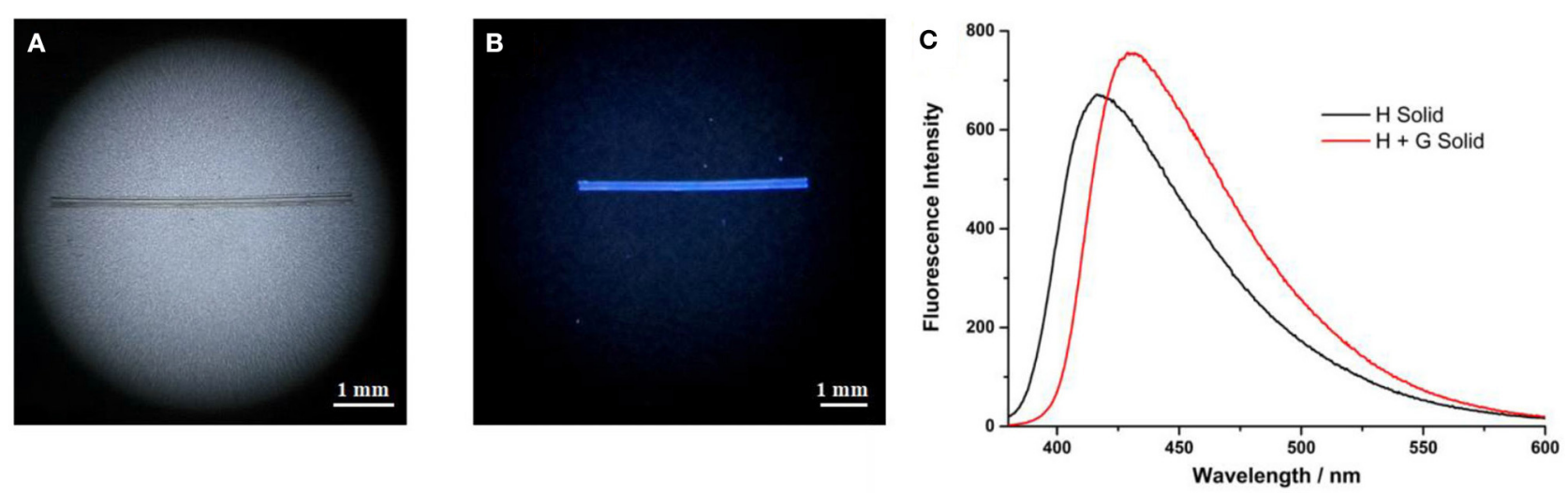

FIGURE 5 | (A) A rod-like fiber formed from $\mathbf{H}$ and $\mathbf{G}$ under visible light; (B) the rod-like fiber under UV (365 nm) lamp irradiation; and (C) fluorescence spectra of $\mathbf{H}$ and $\mathbf{H}-\mathbf{G}$ in the solid state, $\lambda_{\mathrm{ex}}=365 \mathrm{~nm}$.

\section{EXPERIMENTAL}

\section{General}

All chemicals, reagents, and solvents were purchased from commercial suppliers and used, unless otherwise stated, without further purification. If needed, solvents were dried by literatureknown procedures. All yields were given as isolated yields. The ${ }^{1} \mathrm{H}$ NMR and ${ }^{13} \mathrm{C}$ NMR spectra were recorded with a Bruker AVANCE III (300 MHz) spectrometer and calibrated against the residual proton signal or natural abundance carbon resonance of the used deuterated solvent from tetramethylsilane as the internal standard. The chemical shifts $\delta$ are indicated in ppm and the coupling constants $J$ in $\mathrm{Hz}$. The multiplicities are given as $s$ (singlet), $d$ (doublet), dd (doublet of doublets), $t$ (triplet), and $\mathrm{m}$ (multiplet). High-resolution electrospray ionization mass spectra (HR-ESI-MS) were recorded on an Agilent Technologies 6540 UHD Accurate-Mass. Fluorescence measurements were performed on an Agilent Cary Eclipse spectrofluorometer. Viscosity measurements were carried out with Ubbelohde microviscometers (Shanghai Liangjing Glass Instrument Factory, $0.40 \mathrm{~mm}$ inner diameter) at $298 \mathrm{~K}$ in chloroform and acetonitrile.

\section{Synthesis of Compound H}

To a solution of compound $\mathbf{5}(237 \mathrm{mg}, 1.0 \mathrm{mmol})$ in THF $(15 \mathrm{~mL})$ was added compound A $(1.26 \mathrm{~g}, 3.0 \mathrm{mmol})$ and 4-dimethylaminopyridine $(18 \mathrm{mg}, 0.15 \mathrm{mmol})$ at room temperature under $\mathrm{N}_{2}$ atmosphere. Then the $\mathrm{Et}_{3} \mathrm{~N}(303 \mathrm{mg}$, $3.0 \mathrm{mmol}$ ) was added with vigorous stirred over $15 \mathrm{~min}$. The reaction mixture was heated at $70^{\circ} \mathrm{C}$ for $2 \mathrm{~h}$ and then poured into water $(100 \mathrm{~mL})$. The resulting mixture was extracted with DCM $(50 \mathrm{~mL} \times 3)$ and the combined extracts were washed with $\mathrm{H}_{2} \mathrm{O}(100 \mathrm{~mL} \times 3)$, brine $(50 \mathrm{~mL} \times 3)$, dried over anhydrous $\mathrm{Na}_{2} \mathrm{SO}_{4}$ and concentrated under reduced pressure. The resulting residue was chromatographed over silica gel (DCM:MeOH $=$ $60: 1, \mathrm{v} / \mathrm{v}$ ) to afford compound $\mathbf{H}$ as a light yellow solid $(460 \mathrm{mg}$, $0.46 \mathrm{mmol}$ ), yield: $46 \% .{ }^{1} \mathrm{H}$ NMR $\left(300 \mathrm{MHz}, \mathrm{CDCl}_{3}\right): \delta(\mathrm{ppm})$ $=7.98(\mathrm{~d}, J=9.0 \mathrm{~Hz}, 2 \mathrm{H}, \operatorname{Ar} H), 7.85(\mathrm{dd}, J=8.4,2.1 \mathrm{~Hz}, 2 \mathrm{H}$, $\operatorname{Ar} H), 7.74(\mathrm{~d}, J=8.7 \mathrm{~Hz}, 2 \mathrm{H}, \operatorname{Ar} H), 7.69(\mathrm{~d}, J=1.8 \mathrm{~Hz}, 2 \mathrm{H}$,
$\operatorname{Ar} H), 7.54(\mathrm{~s}, 1 \mathrm{H}$, alkene- $H), 7.32(\mathrm{~m}, 4 \mathrm{H}, \operatorname{Ar} H), 6.96(\mathrm{~d}, J=$ $8.7 \mathrm{~Hz}, 2 \mathrm{H}, \mathrm{ArH}), 4.33-4.19\left(\mathrm{~m}, 8 \mathrm{H},-\mathrm{OCH}_{2} \mathrm{CH}_{2} \mathrm{O}-\right), 4.03-3.93$ $\left(\mathrm{m}, 8 \mathrm{H},-\mathrm{OCH}_{2} \mathrm{CH}_{2} \mathrm{O}-\right), 3.82\left(\mathrm{~m}, 8 \mathrm{H},-\mathrm{OCH}_{2} \mathrm{CH}_{2} \mathrm{O}-\right), 3.76(\mathrm{~m}$, $8 \mathrm{H},-\mathrm{OCH}_{2} \mathrm{CH}_{2} \mathrm{O}-$ ), 3.69 (s, $16 \mathrm{H},-\mathrm{OCH}_{2} \mathrm{CH}_{2} \mathrm{O}-$ ). ${ }^{13} \mathrm{C}$ NMR (75 $\left.\mathrm{MHz}, \mathrm{CDCl}_{3}\right): \delta(\mathrm{ppm})=164.6,164.5,153.7,153.7,152.6,151.8$, $148.5,141.2,132.0,131.2,130.6,127.2,124.9,124.8,122.6,122.5$, $121.7,121.6,117.9,114.9,112.3,110.8,71.4,71.3,71.2,71.1$, 71.0, 71.0, 70.6, 69.6, 69.5, 69.4, 69.2. HR-ESI-MS: $\mathrm{m} / \mathrm{z}$ calcd for $\left[\mathrm{C}_{53} \mathrm{H}_{64} \mathrm{NO}_{18}\right]^{+}=1002.4118$, found $=1002.4120$.

\section{CONCLUSION}

In summary, we have successfully synthesized a cyanostilbene motif bridged ditopic B21C7 compound, which exhibits good AIE property and vapochromic behavior. Supramolecular polymers can be fabricated by such a host compound with a ditopic dialkylammonium salt guest. The host-guest supramolecular polymerization was fully characterized by concentration-dependent ${ }^{1} \mathrm{H} \mathrm{NMR}$, viscosity measurements, and fiber formation test. Fluorescent properties of the supramolecular polymers in the solid state are also studied, which suggests that the supramolecular polymers can enhance the AIE of the individual host. The FSP described in this work may have potential applications in the field of dynamic luminescent materials.

\section{DATA AVAILABILITY STATEMENT}

The original contributions generated for the study are included in the article/Supplementary Material, further inquiries can be directed to the corresponding author/s.

\section{AUTHOR CONTRIBUTIONS}

TX conceived and designed the study and wrote and revised the manuscript. HW conducted the synthetic experiments. All authors analyzed and interpreted the data. 


\section{ACKNOWLEDGMENTS}

We gratefully thank the financial support from the National Natural Science Foundation of China (21702020).

\section{REFERENCES}

Aida, T., Meijer, E. W., and Stupp, S. I. (2012). Functional supramolecular polymers. Science 335, 813-817. doi: 10.1126/science.1205962

Chen, Y., Sun, S., Lu, D., Shi, Y., and Yao, Y. (2019). Water-soluble supramolecular polymers constructed by macrocycle-based host-guest interactions. Chin. Chem. Lett. 30, 37-43. doi: 10.1016/j.cclet.2018.10.022

Cheng, M., Zhang, J., Ren, X., Guo, S., Xiao, T., Hu, X. Y., et al. (2017). Acid/base-controllable fluorescent molecular switches based on cryptands and basic N-heteroaromatics. Chem. Commun. 53, 11838-11841. doi: 10.1039/C7CC07469G

Datta, S., Kato, Y., Higashiharaguchi, S., Aratsu, K., Isobe, A., Saito, T., et al. (2020). Self-assembled poly-catenanes from supramolecular toroidal building blocks. Nature 583, 400-405. doi: 10.1038/s41586-020-2445-Z

Dong, S., Leng, J., Feng, Y., Liu, M., Stackhouse, C. J., Schonhals, A., et al. (2017). Structural water as an essential comonomer in supramolecular polymerization. Sci. Adv. 3:eaao0900. doi: 10.1126/sciadv.aao0900

Gu, X., Yao, J., Zhang, G., Yan, Y., Zhang, C., Peng, Q., et al. (2012). Polymorphismdependent emission for di(p-methoxylphenyl)dibenzofulvene and analogues: optical waveguide/amplified spontaneous emission behaviors. Adv. Funct. Mater. 22, 4862-4872. doi: 10.1002/adfm.201201482

Guo, D.-S., Chen, S., Qian, H., Zhang, H.-Q., and Liu, Y. (2010). Electrochemical stimulus-responsive supramolecular polymer based on sulfonatocalixarene and viologen dimers. Chem. Commun. 46, 2620-2622. doi: 10.1039/b925157j

Han, Y., Tian, Y., Li, Z., and Wang, F. (2018). Donor-acceptor-type supramolecular polymers on the basis of preorganized molecular tweezers/guest complexation. Chem. Soc. Rev. 47, 5165-5176. doi: 10.1039/C7CS00802C

Harada, A., Takashima, Y., and Nakahata, M. (2014). Supramolecular polymeric materials via cyclodextrin-guest interactions. Acc. Chem. Res. 47, 2128-2140. doi: 10.1021/ar500109h

Hong, Y., Lam, J. W. Y., and Tang, B. Z. (2011). Aggregation-induced emission. Chem. Soc. Rev. 40, 5361-5388. doi: 10.1039/c1cs15113d

Ji, X., Yao, Y., Li, J., Yan, X., and Huang, F. (2013). A supramolecular cross-linked conjugated polymer network for multiple fluorescent sensing. J. Am. Chem. Soc. 135, 74-77. doi: 10.1021/ja3108559

Kim, H.-J., Nandajan, P. C., Gierschner, J., and Park, S. Y. (2018). Light-harvesting fluorescent supramolecular block copolymers based on cyanostilbene derivatives and cucurbit[8]urils in aqueous solution. Adv. Funct. Mater. 28:1705141. doi: 10.1002/adfm.201705141

Kumawat, L. K., Abogunrin, A. A., Kickham, M., Pardeshi, J., Fenelon, O., Schroeder, M., et al. (2019). Squaramide-naphthalimide conjugates as "turn-on" fluorescent sensors for bromide through an aggregationdisaggregation approach. Front. Chem. 7:354. doi: 10.3389/fchem.2019. 00354

Lavrenova, A., Balkenende, D. W. R., Sagara, Y., Schrettl, S., Simon, Y. C., and Weder, C. (2017). Mechano- and thermoresponsive photoluminescent supramolecular polymer. J. Am. Chem. Soc. 139, 4302-4305. doi: 10.1021/jacs.7b00342

Lee, S., Chen, C.-H., and Flood, A. H. (2013). A pentagonal cyanostar macrocycle with cyanostilbene $\mathrm{CH}$ donors binds anions and forms dialkylphosphate [3] rotaxanes. Nat. Chem. 5, 704-710. doi: 10.1038/nchem.1668

Li, B., He, T., Shen, X., Tang, D., and Yin, S. (2019). Fluorescent supramolecular polymers with aggregation induced emission properties. Polym. Chem. 10, 796-818. doi: 10.1039/C8PY01396A

Li, S.-L., Xiao, T., Lin, C., and Wang, L. (2012). Advanced supramolecular polymers constructed by orthogonal self-assembly. Chem. Soc. Rev. 41, 5950-5968. doi: $10.1039 / \mathrm{c} 2 \mathrm{cs} 35099 \mathrm{~h}$

Li, X., Wang, L., Deng, Y., Luo, Z., Zhang, Q., Dong, S., et al. (2018). Preparation of cross-linked supramolecular polymers based on benzo-21-crown-7/secondary

\section{SUPPLEMENTARY MATERIAL}

The Supplementary Material for this article can be found online at: https://www.frontiersin.org/articles/10.3389/fchem. 2020.610093/full\#supplementary-material

ammonium salt host-guest interactions. Chem. Commun. 54, 12459-12462. doi: 10.1039/C8CC07657J

Lu, C., Zhang, M., Tang, D., Yan, X., Zhang, Z., Zhou, Z., et al. (2018). Fluorescent metallacage-core supramolecular polymer gel formed by orthogonal metal coordination and host-guest interactions. J. Am. Chem. Soc. 140, 7674-7680. doi: $10.1021 /$ jacs.8b03781

Qi, L., Ding, Y., Xiao, T., Wu, H., Diao, K., Bao, C., et al. (2020). Supramolecular polymerization of dioxyphenylene bridged UPy derivatives and their hostguest behaviors with the bipyridinium-based cyclophane. Chin. J. Org. Chem. doi: 10.6023/cjoc202006070

Shi, B., Jie, K., Zhou, Y., Zhou, J., Xia, D., and Huang, F. (2016). Nanoparticles with near-infrared emission enhanced by pillararene-based molecular recognition in water. J. Am. Chem. Soc. 138, 80-83. doi: 10.1021/jacs.5b11676

Shi, B., Zhou, Z., Vanderlinden, R. T., Tang, J.-H., Yu, G., Acharyya, K., et al. (2019). Spontaneous supramolecular polymerization driven by discrete platinum metallacycle-based host-guest complexation. J. Am. Chem. Soc. 141, 11837-11841. doi: 10.1021/jacs.9b06181

Sun, G., Qian, W., Jiao, J., Han, T., Shi, Y., Hu, X.-Y., et al. (2020). A highly efficient artificial light-harvesting system with two-step sequential energy transfer based on supramolecular self-assembly. J. Mater. Chem. A 8, 9590-9596. doi: 10.1039/D0TA03169K

Wagner, W., Wehner, M., Stepanenko, V., and Wurthner, F. (2019). Supramolecular block copolymers by seeded living polymerization of perylene bisimides. J. Am. Chem. Soc. 141, 12044-12054. doi: 10.1021/jacs.9b04935

Wang, S., Xu, Z., Wang, T., Xiao, T., Hu, X.-Y., Shen, Y.-Z., et al. (2018). Warm/cool-tone switchable thermochromic material for smart windows by orthogonally integrating properties of pillar[6]arene and ferrocene. Nat. Commun. 9:1737. doi: 10.1038/s41467-018-03827-3

Wang, Y., Cai, Y., Cao, L., Cen, M., Chen, Y., Zhang, R., et al. (2019). An amphiphilic metallaclip with enhanced fluorescence emission in water: synthesis and controllable self-assembly into multi-dimensional microstructures. Chem. Commun. 55, 10132-10134. doi: 10.1039/C9CC04809J

Wehner, M., and Würthner, F. (2020). Supramolecular polymerization through kinetic pathway control and living chain growth. Nat. Rev. Chem. 4, 38-53. doi: 10.1038/s41570-019-0153-8

Wei, P., Yan, X., and Huang, F. (2015). Supramolecular polymers constructed by orthogonal self-assembly based on host-guest and metal-ligand interactions. Chem. Soc. Rev. 44, 815-832. doi: 10.1039/C4CS00327F

Xiao, T., Feng, X., Wang, Q., Lin, C., Wang, L., and Pan, Y. (2013). Switchable supramolecular polymers from the orthogonal self-assembly of quadruple hydrogen bonding and benzo-21-crown-7-secondary ammonium salt recognition. Chem. Commun. 49, 8329-8331. doi: 10.1039/c3cc44525a

Xiao, T., Qi, L., Zhong, W., Lin, C., Wang, R., and Wang, L. (2019a). Stimuli-responsive nanocarriers constructed from pillar[n]arene-based supraamphiphiles. Mater. Chem. Front. 3, 1973-1993. doi: 10.1039/C9QM00428A

Xiao, T., and Wang, L. (2018). Recent advances of functional gels controlled by pillar[n]arene-based host-guest interactions. Tetrahedron Lett. 59, 1172-1182. doi: 10.1016/j.tetlet.2018.02.028

Xiao, T., Wu, H., Sun, G., Diao, K., Wei, X., Li, Z.-Y., et al. (2020a). An efficient artificial light-harvesting system with tunable emission in water constructed from H-bonded AIE supramolecular polymer and Nile Red. Chem. Commun. 56, 12021-12024. doi: 10.1039/D0CC05077F

Xiao, T., Xu, L., Götz, J., Cheng, M., Würthner, F., Gu, J., et al. (2019b). Supramolecular polymerization and cyclization of dioxynaphthalene motif bridged bifunctional UPys: minor variations in the molecular skeleton and drastic differences in self-assembly. Mater. Chem. Front. 3, 2738-2745. doi: 10.1039/C9QM00595A

Xiao, T., Xu, L., Wang, J., Li, Z.-Y., Sun, X.-Q., and Wang, L. (2019c). Biomimetic folding of small organic molecules driven by multiple 
non-covalent interactions. Org. Chem. Front. 6, 936-941. doi: 10.1039/C9QO $00089 \mathrm{E}$

Xiao, T., Xu, L., Zhong, W., Zhou, L., Sun, X.-Q., Hu, X.-Y., et al. (2018). Advanced functional materials constructed from pillar[n]arenes. Isr. J. Chem. 58, 1183-1193. doi: 10.1002/ijch.201800026

Xiao, T., Xu, L., Zhou, L., Sun, X.-Q., Lin, C., and Wang, L. (2019d). Dynamic hydrogels mediated by macrocyclic host-guest interactions. J. Mater. Chem. B 7, 1526-1540. doi: 10.1039/C8TB02339E

Xiao, T., Zhong, W., Qi, L., Gu, J., Feng, X., Yin, Y., et al. (2019e). Ring-opening supramolecular polymerization controlled by orthogonal noncovalent interactions. Polym. Chem. 10, 3342-3350. doi: 10.1039/C9PY00312F

Xiao, T., Zhong, W., Xu, L., Sun, X.-Q., Hu, X.-Y., and Wang, L. (2019f). Supramolecular vesicles based on pillar[n]arenes: design, construction, and applications. Org. Biomol. Chem. 17, 1336-1350. doi: 10.1039/C8OB03095B

Xiao, T., Zhong, W., Zhou, L., Xu, L., Sun, X.-Q., Elmes, R. B. P., et al. (2019g). Artificial light-harvesting systems fabricated by supramolecular host-guest interactions. Chin. Chem. Lett. 30, 31-36. doi: 10.1016/j.cclet.2018.05.034

Xiao, T., Zhou, L., Sun, X.-Q., Huang, F., Lin, C., and Wang, L. (2020b). Supramolecular polymers fabricated by orthogonal self-assembly based on multiple hydrogen bonding and macrocyclic host-guest interactions. Chin. Chem. Lett. 31, 1-9. doi: 10.1016/j.cclet.2019.05.011

Xiao, T., Zhou, L., Wei, X., Li, Z., and Sun, X. (2020c). Supramolecular copolymers driven by quadruple hydrogen bonding and host-guest interactions. Chin. J. Org. Chem. 40, 944-949. doi: 10.6023/cjoc201911014

Xiao, T., Zhou, L., Xu, L., Zhong, W., Zhao, W., Sun, X.-Q., et al. (2019h). Dynamic materials fabricated from water soluble pillar[n]arenes bearing triethylene oxide groups. Chin. Chem. Lett. 30, 271-276. doi: 10.1016/j.cclet.2018.05.039

Yang, L., Tan, X., Wang, Z., and Zhang, X. (2015). Supramolecular polymers: historical development, preparation, characterization, and functions. Chem. Rev. 115, 7196-7239. doi: 10.1021/cr500633b
Zhang, C., Li, S., Zhang, J., Zhu, K., Li, N., and Huang, F. (2007). Benzo-21-crown-7/secondary dialkylammonium salt [2]Pseudorotaxane- and [2]rotaxane-type threaded structures. Org. Lett. 9, 5553-5556. doi: 10.1021/ol7 $02510 \mathrm{c}$

Zhang, C.-W., Ou, B., Jiang, S.-T., Yin, G.-Q., Chen, L.-J., Xu, L., et al. (2018). Cross-linked AIE supramolecular polymer gels with multiple stimuliresponsive behaviours constructed by hierarchical self-assembly. Polym. Chem. 9, 2021-2030. doi: 10.1039/C8PY00226F

Zhang, M., Yin, S., Zhang, J., Zhou, Z., Saha, M. L., Lu, C., et al. (2017). Metallacycle-cored supramolecular assemblies with tunable fluorescence including white-light emission. Proc. Natl. Acad. Sci. U.S.A. 114, 3044-3049. doi: 10.1073/pnas.1702510114

Zhang, Q., Li, T., Duan, A., Dong, S., Zhao, W., and Stang, P. J. (2019). Formation of a supramolecular polymeric adhesive via water-participant hydrogen bond formation. J. Am. Chem. Soc. 141, 8058-8063. doi: 10.1021/jacs.9b02677

Zheng, W., Chen, L.-J., Yang, G., Sun, B., Wang, X., Jiang, B., et al. (2016). Construction of smart supramolecular polymeric hydrogels cross-linked by discrete organoplatinum(II) metallacycles via post-assembly polymerization. J. Am. Chem. Soc. 138, 4927-4937. doi: 10.1021/jacs.6b01089

Conflict of Interest: The authors declare that the research was conducted in the absence of any commercial or financial relationships that could be construed as a potential conflict of interest.

Copyright (C) $2020 \mathrm{Wu}$ and Xiao. This is an open-access article distributed under the terms of the Creative Commons Attribution License (CC BY). The use, distribution or reproduction in other forums is permitted, provided the original author(s) and the copyright owner(s) are credited and that the original publication in this journal is cited, in accordance with accepted academic practice. No use, distribution or reproduction is permitted which does not comply with these terms. 